\section{Splenic Hydatid Cyst Calcified}

Amine Slaoui*, Souhail Regragui, Alae Touzani, Tarik Karmouni, Khalid el Khader, Abdelatif Koutani and Ahmed Andaloussi lbn Attya

Department of Urology B, Ibn Sina University Hospital, Rabat, Morocco
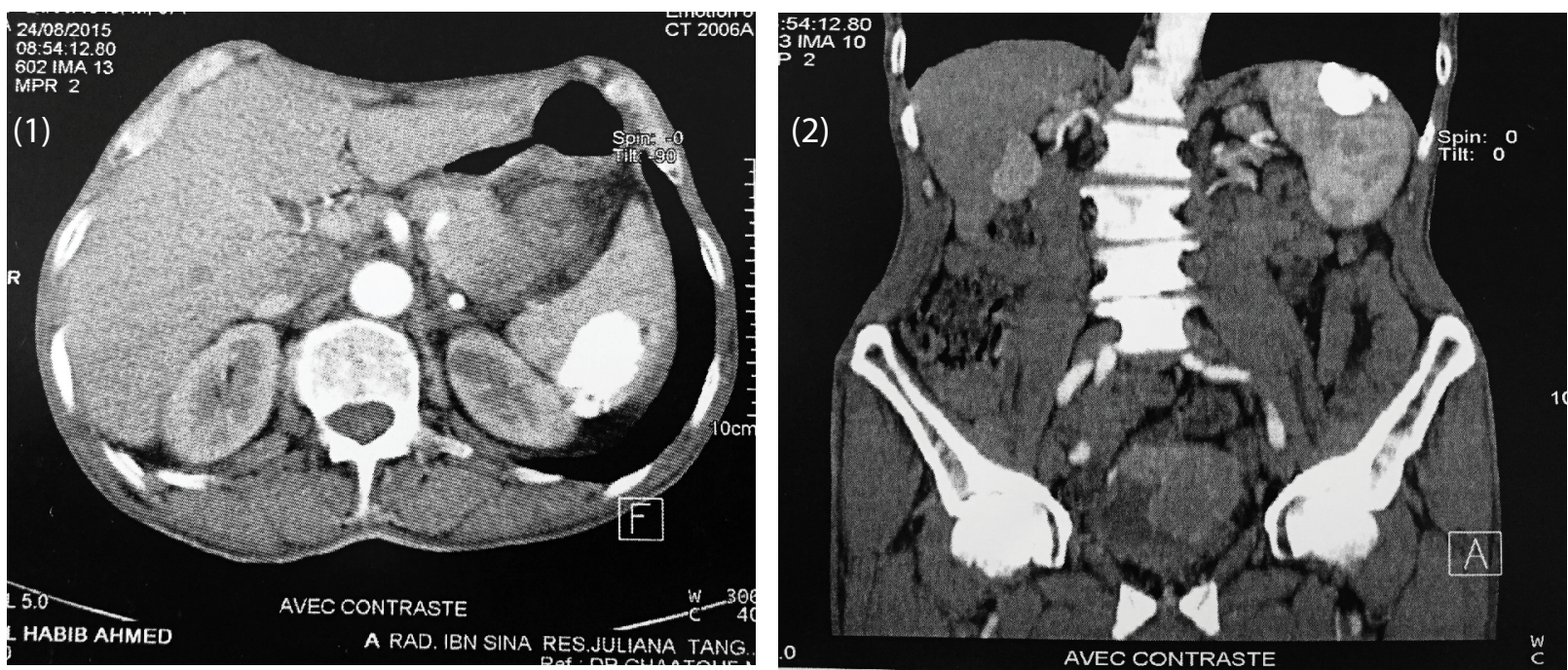

Figure 1: Hydatid cyst of the spleen (coronal section). Figure 2: Hydatid cyst of the spleen (Reconstruction).

\section{Clinical Image}

A patient of 54 years with a chronic history as smoking was hospitalized in urology department for care of a bladder tumor. As part of its staging, a thoraco- abdominopelvic CT was requested. He revealed the presence of a calcified hydatid cyst spleen, liver and lung were unharmed (Figures 1 and 2). The patient showed no hyper eosinophilia and hydatid serology was positive. The splenic hydatid cyst was asymptomatic and calcified that's why the therapeutic decision was abstention and monitoring. To this day the patient had no complications.

*Corresponding author: Amine Slaoui, Department of Urology B, Ibn Sina University Hospital, Rabat,Morocco, Tel: 0032474480267; E-mail: amineslaoui05@gmail.com

Citation: Slaoui A, Regragui S, Touzani A, Karmouni T, Khader Kl et al.(2018) Splenic Hydatid Cyst Calcified. Int J Clin Med Imaging 4: 598. doi:10.4172/23760249.1000598

Copyright: (C) 2018 Slaoui A et al. This is an open-access article distributed under the terms of the Creative Commons Attribution License, which permits unrestricted use, distribution, and reproduction in any medium, provided the original author and source are credited. 